\title{
PMD23 ÇELİĞİNİN TORNALANMASINDA CBN KESİCi UÇLARIN KESME PERFORMANSININ YÜZEY PÜRÜZLÜLÜĞÜ VE TAKIM AŞINMASI ÜZERİNDEKİ ETKİLERİNİN BELİRLENMESİ
}

\author{
Alaattin KACAL ${ }^{1}$, Ferhat YILDIRIM ${ }^{2}$ \\ ${ }^{1}$ Dumlupınar Üniversitesi, Simav Teknoloji Fakültesi, İmalat Mühendisliği Bölümü, Simav, Kütahya \\ ${ }^{2}$ Dumlupınar Üniversitesi, Simav Teknik Eğitim Fakültesi, Makine Eğitimi Bölümü, Simav, Kütahya \\ alaattin.kacal@dpu.edu.tr, ferhat.yildirim@dpu.edu.tr
}

(Geliş/Received: 20.02.2015; Kabul/Accepted: 03.12.2015)

ÖZET

$\mathrm{Bu}$ çalışmada, sertleştirilmiş (60 HRC) PMD-23 toz metal çeliğinin torna ile işleme performansı, yüzey pürüzlülüğü ve takım aşınması açısından değerlendirilmiştir. Deneyler üç farklı kesme hızı, ilerleme ve kesme derinliğinde kuru şartlarda yapılmıştır. Kesme parametrelerinin yüzey pürüzlülüğü (Ra) üzerindeki etkilerini belirlemek için varyans analizi (ANOVA) yapılmıştır. Elde edilen sonuçlar kesme derinliğinin Ra'nın değişimi üzerinde en etkin parametre olduğunu göstermiştir. Ayrıca, takım aşınması tipi ve mekanizmalarını belirlemek için taramalı elektron mikroskobu kullanılarak kesici uçların görüntüleri alınmıştır. Yapılan incelemelerde, takım üzerinde kesici uçta krater aşınması ve az miktarda da serbest yüzey aşınması oluştuğu görülmüştür. İlerleme ve kesme derinliği değerlerindeki artışa bağlı olarak Ra değerleri artmıştır. ANOVA sonuçlarına göre ise Ra üzerindeki en etkin parametrenin kesme derinliği olduğu, ikinci dereceden en etkili parametrenin ise ilerleme olduğu tespit edilmiştir.

Anahtar Kelimeler: CBN kesici uç, yüzey pürüzlülüğü, takım aşınması

\section{DETERMINING THE EFFECTS OF CBN CUTTING INSERT'S CUTTING PERFORMANCE ON SURFACE ROUGHNESS AND TOOL WEAR AT TURNING OF PMD 23 STEEL}

\begin{abstract}
In this work, the cutting performance of $\mathrm{CBN}$ insert was investigated in terms of surface roughness and tool wear in turning of hardened (60 HRC) PMD-23 powder metallurgical steel. The turning tests were performed with three different cutting speeds, feed and depth of cuts in dry cutting condition. Analysis of Variance (ANOVA) was performed in order to determining of the effect of cutting parameters on the average surface roughness (Ra). The experimental results and indicated that the depth of cut was most significant parameter on changes in Ra. Furthermore, images of cutting insert used in turning tests were taken using Scanning Electron Microscope (SEM) for determining of the wear types and its mechanisms. According to the image investigation, crater wear and slightly flank wear were observed in cutting insert. Depending on the increase in feed and depth of cut values $\mathrm{Ra}$ values were increased. ANOVA results showed that the most influential parameter is depth of cut on the values of $\mathrm{Ra}$ and the second influential parameter is feed.
\end{abstract}

Keywords: CBN insert, surface roughness, tool wear

\section{GÍRISŞS (INTRODUCTION)}

Toz metalürjisi (T/M) yönteminin, son biçimde ya da son biçime çok yakın parça üretimi, az miktarda atık oluşumu, geniş toz kompozisyonları ve uygulama alanı gibi özellikleri ile kullanımı giderek yaygınlaşmaktadır. $\mathrm{Bu}$ tip parçalar kütle/yük taşıma oranlarına bağlı olarak çok hafif olmalarına karşın 
büyük yükleri taşıyabilmektedirler $[1,2]$. Bu yöntemde elde edilen ürünler her ne kadar son ölçülere yakın olsalar da zaman zaman talaşlı işleme operasyonları gerekebilir. T/M yöntemi ile üretilen parçaların talaşlı imalatı söz konusu olduğunda ise laboratuvar çalışmaları ve endüstriyel alandaki çalışmalar işleme operasyonlarının karmaşık olduğunu ortaya koymaktadır. Kimyasal kompozisyon, mikro yapı, yüzey özellikleri gibi etkenler toz metal parçaların işlenebilirlikleri üzerinde farklı oranlarda etkilidirler. Örneğin gözenekli yapılar kesilme esnasında kesikli kesme benzeri bir durum ortaya çıkararak kesici takım üzerinde olumsuz etkiler doğurmaktadır. Bunun yanı sıra, takım-talaş ara yüzeyinde malzeme yoğunluğuna bağlı olarak ortaya çıkan kimyasal reaksiyonlar ve oksitlenme kesici takım ömrünü azaltmaktadır. Bu tür malzemeler için yüksek kimyasal kararlılığa ve abrasif aşınma direncine sahip, mümkün olduğunca keskin kenarlı kesici takımlar kullanılmalıdır. Malzemenin özelliklerine bağlı olarak kesici takım kalitelerinin de uygun seçilmesi önemlidir. Özellikle karbür, seramik ve CBN kesici takımlar kullanılmaktadır [3]. Endüstriyel alanda kullanılan çelik türlerinin üretiminde $\mathrm{T} / \mathrm{M}$ yönteminin kullanılmasında son yıllarda belirgin bir artış gözlenmektedir. Özellikle de bu yöntemle üretilen takım çelikleri yüksek mekanik özellikleri nedeni ile tercih edilmektedirler. Buna paralel olarak da bu tür malzemelerin işlenebilirlik özelliklerinin araştırılmasına olan ilgi de artmıştır. Takım ömrü, aşınma mekanizmaları, kesme kuvvetleri, yüzey pürüzlülüğü, geometrik tamlık gibi konularda toz metalürjisi çelikler üzerinde çalışmalar yapılmaktadır. $\mathrm{Bu}$ çalışmalar için tornalama, frezeleme ve delik delme ve işleme operasyonları hedef operasyon tipleri olarak göze çarpmaktadır. 260 HB sertliğe kadar sertleştirilmiş $\mathrm{T} / \mathrm{M}$ çeliğin farklı geometrilerdeki TiAlN ile PVD kaplamalı karbür kesici takımlarla değişik kesme parametreleri ile yüksek hızlarda tornalanmış, kesme parametrelerinin takım aşınması, yüzey pürüzlülüğü, kesicilerin çıkan talaşlar ve şekilleri üzerindeki etkisi araştırılmıştır. Deney sonuçlarına göre, kesme hızı, ilerleme ve kesici uç yarıçapı parametrelerinden kesici yan yüzey aşınmasına en fazla etkiyi gösteren kesme parametresinin kesme hızı olduğu görülmüştür. Deney numunesi malzemesi ve kesici takım ikilisi için kesme hızı arttıkça yüzey kalitesi iyileşmiştir [4]. T/M yöntemi ile üretilmiş ve sertleştirilmiş PMD-23 çeliğinin kaplamalı seramik kesici ile tornalanmasında takım aşınmasının ve yüzey pürüzlülüğünün değerlendirilmesi üzerine yapılan çalışmada, ilerleme değerlerindeki değişimin yüzey pürüzlülüğü üzerinde önemli etkilerinin olduğu belirtilmiştir. SEM fotoğraflarında krater aşınmasının oluştuğu görülmüştür [5]. Bir başka çalışmada ise, T/M yöntemi ile üretilmiş K390 soğuk iş takım çeliği sertleştirilmiş ve üç farklı sıcaklıkta temperlenerek işlenebilirlik özellikleri araştırılmıştır. Kaplamalı CBN kesici takım kullanılarak kesme hızı, ilerleme ve temperleme sıcaklıklarının kesme kuvvetleri, takım aşınması ve yüzey pürüzlülüğü üzerindeki etkileri incelenmiştir. Deneyler sonucunda, taşlama operasyonlarında elde edilen yüzey pürüzlülük değerlerine yaklaşan yüzey pürüzlülüğü değeri (Ra:0,15 $\mu \mathrm{m}$ ) ölçülmüştür. Ayrıca çalışmada yüzey kalitesi açısından uygun olan parametreler önerilmiştir [6]. Aynı malzeme ile yapılan frezeleme çalışmasında da oldukça düşük yüzey pürüzlülüğü değerleri elde edilmiştir [7]. Çeliklerin sertleştirildikten sonra tornalanması, taşlama operasyonlarına yakın değerlerde yüzey kalitesi elde etme, kısa işleme süresi, kesme sıvısına ihtiyaç olmaması gibi nedenlerden dolayı avantajlıdır. Ancak takım ömrü açısından malzeme sertliği dikkate alınarak uygun kesici takım ve kesme parametrelerinin belirlenmesi oldukça önemlidir [8]. Geleneksel çeliklerde olduğu gibi T/M çeliklerde de sertleştirildikten sonra talaşlı imalat uygulamalarına rastlanmaktadır. Sertleştirilmiş AISI 52100 rulman çeliğinin ince tornalama operasyonlarında karma seramik kesici takım geometrisinin yüzey pürüzlülüğü üzerine etkisinin araştırıldığı çalışmada, en etkin parametrelerin sırasıyla, ilerleme, kesici uç yarıçapı ve kesme hızı olduğu belirtilmiştir. Efektif talaş açısının etkisi daha az olmuştur. Ayrıca Cevap Yüzey metodu kullanılarak matematiksel bir yöntem önerilmiştir [9]. Benzer malzeme üzerine yapılan başka bir çalışmada ise $\mathrm{Rz} / \mathrm{Ra}$ değerlerinin ilerlemeden etkilendiği rapor edilmiştir [10]. Bartarya ve Choudhury aynı malzeme ile yaptıkları çalışmada benzer sonuçlara işaret etmişlerdir [11]. Aouici ve diğerleri, AISI H11 malzemede kesme hızı, ilerleme, kesme derinliği ve iş parçası sertliğinin kesme kuvvetleri ve yüzey pürüzlülüğü üzerindeki etkilerini incelemişler, CBN kesici kullandıkları çalışmadan elde ettikleri sonuçları istatistiksel yöntemler kullanarak değerlendirmişlerdir. Kesme kuvvetlerinin öncelikle ilerleme ve iş parçası sertliğinden etkilendiğini aynı şekilde yüzey pürüzlülüğü üzerinde de etkilerinin olduğu belirtmişlerdir [12]. Minimum pürüzlülük (Ra ve $\mathrm{Rz}$ ) amaciyla tornalama parametrelerinin optimizasyonu için AISI 4140 (51 HRC) malzeme ile Taguchi yöntemi kullanılarak yapılan çalışmada, ilerlemenin en etkin parametre olduğu vurgulanmıştır. Geliştirilen model en uygun kesme parametrelerin belirlenmesi için kullanılabilecektir [13]. Poulachon ve diğerleri, AISI D2, AISI H11, AISI 52100 ve 35NiCrMo16 malzemelerini sertleștirdikten sonra CBN kesici ile tornalamışlardır. Krater aşınması ile adhesiv ve kimyasal aşınma mekanizmalarına işaret etmişlerdir [14]. Lalwani ve diğerleri, seramik kesiciler kullanarak su verilmiş MDN 250 çeliğinin tornalanmasında kesme kuvveti bileşenlerinin ve yüzey pürüzlülüğünün değişimini araştırmışlardır. Cevap yüzey metodunu kullanarak deney sonuçlarını analiz etmişlerdir. Deney sonuçlarında düşük kesme hızı aralıklarında fazlaca bir değişim görülmemiştir. İlerleme ve kesme derinliği kesme kuvvetlerinin 
üzerinde etkili olmuştur. İlerleme özellikle ilerleme kuvvetini etkilemektedir. Kesme kuvvetleri ve pürüzlülük için önerilen regresyon eşitliklerinin istatistiksel olarak uygun oldukları görülmüştür [15]. Sert parçaların tornalama operasyonlarında farklı geometriye ve özelliklere sahip seramik kesiciler kullanılarak kesme parametreleri ile yüzey pürüzlülüğü, titreşim, takım ömrü ve takım durumu arasındaki ilişkinin de araştırıldığı görülmektedir [1618]. Su verilmiş AISI D6 soğuk iş takım çeliğinin seramik ve CBN kesicilerle tornalanmasında kesme parametrelerinin optimizasyonu gri ilişkisel analiz yöntemi kullanılarak yapılmıştır. Çalışmada ilerleme en etkin parametre olarak belirtilmiştir. Serbest yüzey ve krater aşınması etkin aşınma tipleri olarak ortaya çıkmıştır [19]. Bu çalışmada, 60 HRC değerinde sertleştirilmiş PMD-23 özel isimli toz metal çeliğinin tornalanmasında yukarıda bahsedilen diğer çalışmalardan farklı olarak CBN kesici takımın performansı araştırılmıştır. $\mathrm{Bu}$ amaçla farklı kesme parametreleri belirlenerek yüzey pürüzlülüğü ve takım aşınması ele alınmıştır. Sonuçların değerlendirilmesi tarama elektron mikroskobu görüntüleri, istatistiksel analiz ve regresyon modeli ile desteklenmiştir.

\section{MALZEME VE YÖNTEM (MATERIAL AND METHOD)}

Deneysel çalışmada kullanılan PMD-23 çeliği toz metalürjisi yöntemi ile üretilmiş soğuk iş takım çeliklerinden biridir. Bu çelik türü özellikle takım ve kalıp endüstrisinde çeşitli mekanik parçaların imalatında tercih edilmektedir. Özellikle 1sıl ișlem sonrasında sergiledikleri mukavemet özellikleri ile öne çıkan çeliklerden olan toz metal çelik gerek ticari satış sertlik değerlerinde gerekse de sertleştirildikten sonra işlenebilmektedirler. PMD-23 çeliğine ait kimyasal bileşim Tablo 1'de verilmiştir. Ø 40x150 mm boyutlarında ve 60 HRC sertlik değerindeki deney numunesinin tornalama deneyleri kesme sıvısı kullanılmadan ayna-punta arasına bağlanarak yapılmıştır. Tornalama deneylerinde sertleştirilmiş çeliklerin işlenmesi için önerilen ve SandvikCoromant tarafindan üretilen SNGA120408 S01030 kodlu 7015 (ISO:H15) kalite değerinde TiN kaplamalı CBN kesici uçlar kullanılmıştır. Kesici uç geometrisine bakıldığında (Şekil 1); 0,1 $\mathrm{mm}$ genişliğinde $30^{\circ}$ 'lik pah kırıldığı ve kesme kenarının yuvarlatıldığı görülmektedir. Deney malzemesi ve kesici uç üreticisi firmanın tavsiyeleri dikkate alınarak Tablo 2'de verilen parametreler belirlenmiş ve toplam 27 adet tornalama deneyi yapılmıştır. Tornalama deneyleri $12 \mathrm{~kW}$ gücünde ve max. 4000 dev/dak devir sayısı sağlayabilen YANG SL-20 CNC torna tezgâhında kuru şartlarda gerçekleştirilmiştir. Deneyler sonrasında ortalama yüzey pürüzlülüğü $(\mathrm{Ra})$ ve takım aşınmaları değerlendirmeye alınarak CBN kesici uçların PMD-23 üzerindeki performansı incelenmiştir. Yüzey pürüzlülüğü ölçümleri için TIME TR200 taşınabilir izleyici uç tip pürüzlülük ölçüm cihazı kullanılmıştır. Yüzey pürüzlülüğü ölçümlerinde örnekleme ve ölçüm uzunlukları ilerleme değerleri dikkate alınarak belirlenmiştir. Ölçülen pürüzlülük değerlerinin ilişki grafikleri çizilerek değerlendirilmiştir. Sonuçların anlamlılıklarını ve deneysel parametrelerin sonuçlar üzerindeki etkilerini tespit etmek amaciyla varyans analizleri yapılmıştır. Takım aşınma tiplerinin, miktarlarının ve mekanizmalarının tespiti için ilk olarak optik mikroskop altında görüntüleri çekilmiş ve ardından SEM görüntüleri alınarak detaylı inceleme yapılmıştır.

Tablo 1. PMD-23 çeliğinin kimyasal bileşimi (ağırlıkça \%) (Chemical composition of PMD-23 steel (\% wt))

\begin{tabular}{|c|c|c|c|c|c|c|c|c|}
\hline $\mathbf{C}$ & $\mathbf{S i}$ & $\mathbf{M n}$ & $\mathbf{P}$ & $\mathbf{S}$ & $\mathbf{C r}$ & $\mathbf{W}$ & $\mathbf{M o}$ & $\mathbf{V}$ \\
\hline 1,29 & 0,26 & 0,26 & 0,027 & 0,02 & 4,04 & 6,32 & 4,87 & 2,79 \\
\hline
\end{tabular}

Tablo 2. Deneysel parametreler (Experimental parameters)

\begin{tabular}{|c|c|c|c|}
\hline \multirow{2}{*}{ Parametreler } & \multicolumn{3}{|c|}{ Seviyeleri } \\
\cline { 2 - 4 } & $\mathbf{1}$ & $\mathbf{2}$ & $\mathbf{3}$ \\
\hline Kesme hızı, Vc (mm/dak) & 150 & 210 & 270 \\
\hline İlerleme, f(mm/dev) & 0,05 & 0,1 & 0,15 \\
\hline Kesme derinliği, ap (mm) & 0,1 & 0,25 & 0,4 \\
\hline
\end{tabular}

3. DENEYSEL BULGULAR VE TARTIŞMA (EXPERIMENTAL RESULTS AND DISCUSSION)

T/M yöntemi ile üretilen ve sertleştirilen PMD-23 çeliğinin $\mathrm{CBN}$ kesicilerle tornalanmasından sonra kesici uç üzerinde meydana gelen aşınma mekanizmalarının tespiti ve buna bağlı olarak takım performansının değerlendirilmesi için kesici uçların SEM görüntüleri alınmış ve değerlendirilmiştir. Şekil 2'de deney numunesinin $270 \mathrm{~m} /$ dak kesme hizı ve $0,15 \mathrm{~mm} / \mathrm{dev}$ ilerleme ve $0,4 \mathrm{~mm}$ kesme derinliği şartlarında tornalanmasından sonra meydana gelen aşınma durumu gösterilmektedir. Genel olarak bakıldığında; kesici uç talaş yüzeyinde kesme derinliği ve ilerleme değerine göre şekillenmiş krater aşınması formu ve yaklaşık olarak $0,016 \mathrm{~mm}$ serbest yüzey aşınması görülmektedir. Serbest yüzey aşınması, takım ömrü, serbest yüzey aşınması kriteri VB açısından oldukça küçük değerdedir. Ayrıca kesici kenar üzerinde az miktarda talaş yapışmaları ve sıvanmaları görülmektedir. Şekil 2c'ye bakıldığında talaş akış yönünde krater yüzeyine sıvanan iş parçası malzemesi görülmektedir. Difüzyon ve abrasif aşınma mekanizmasının bir sonucu olarak ortaya çıkan krater aşınmasının [20] oluşturduğu krater yüzeyi şekillenirken mekanik yüklerin de etkisi ile yüzeye yapışan talaşların kopması kaçınılmazdır. Kopma ile birlikte krater yüzeyi daha fazla iş parçası malzemesinin yapışma olanağı bulabileceği bir pürüzlülüğe bürünür [6]. $\mathrm{Bu}$ durumda kesme işleminin devam etmesi neticesinde krater büyüklüğünün ve/veya derinliğinin artacağı beklenebilir. Bazen yapışan iş parçası malzemesinin oluşturduğu tabakalar kararlılıklarını koruyabildikleri sürece, takım kaplaması gibi davranarak, kesici takımı koruyucu rol oynayabilirler. Şekil $2 \mathrm{~d}$ incelendiğinde mikro düzeyde iş parçası malzemesi yapışmalarının 

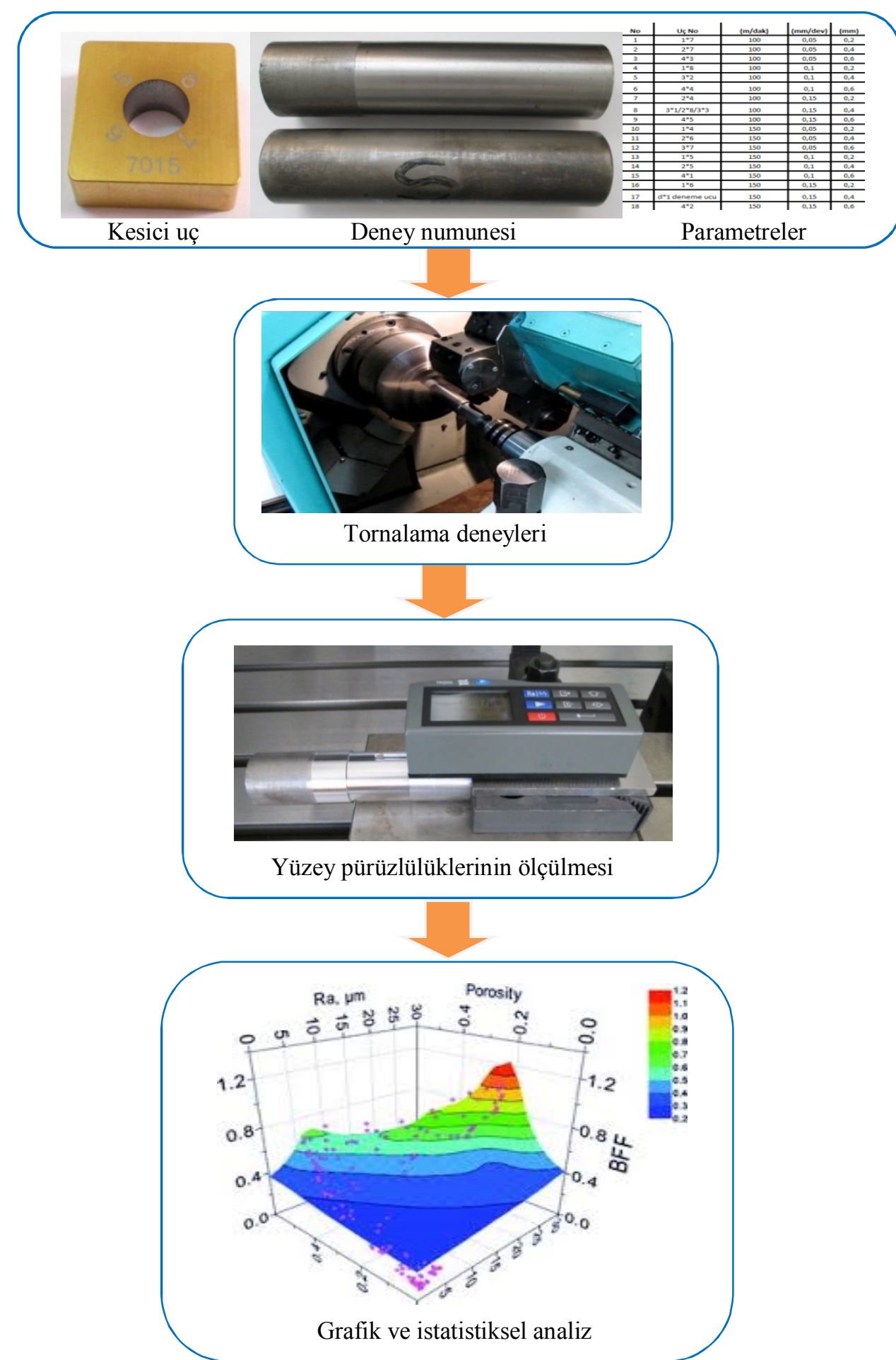

Şekil 1. Deneysel yöntem akış şeması (Experimental method flowchart)

ve parçacık kopmalarının olduğu görülmektedir. Sertleştirilmiş olan malzeme içinde dağılmış olan sert parçacıkların kesme sırasındaki değişken yüklemeler oluşturması mikro düzeyde kopmalara sebep olabilir ve takım üzerinde talaşın temas ettiği yüzeyleri y1pratabilir.

Az miktardaki serbest yüzey aşınmasına yakından bakıldığında (Şekil 2e); sertleştirilmiş deney numunesinin içindeki bulunması olası sert martenzit parçacıkların neden olduğu abrasif aşınma mekanizmasinin [21] sonucu olan abrazyon izleri kesmeye katılan kesici kenar boyunca görülmektedir. Birbirine paralel derin oluklar şeklindeki abrazyon izlerinin yapısına bakılırsa, sertleştirilmiş olan iş parçasının kesme kenarı üzerindeki güçlü etkisi açıkça görülmektedir. CBN kesici uç ile tornalanan parçanın sertleştirilmiş ve T/M çelik olması aşınma mekanizmalarının daha hızlı gelişmesine ve etkisini artırmasına yol açabilmektedir. 

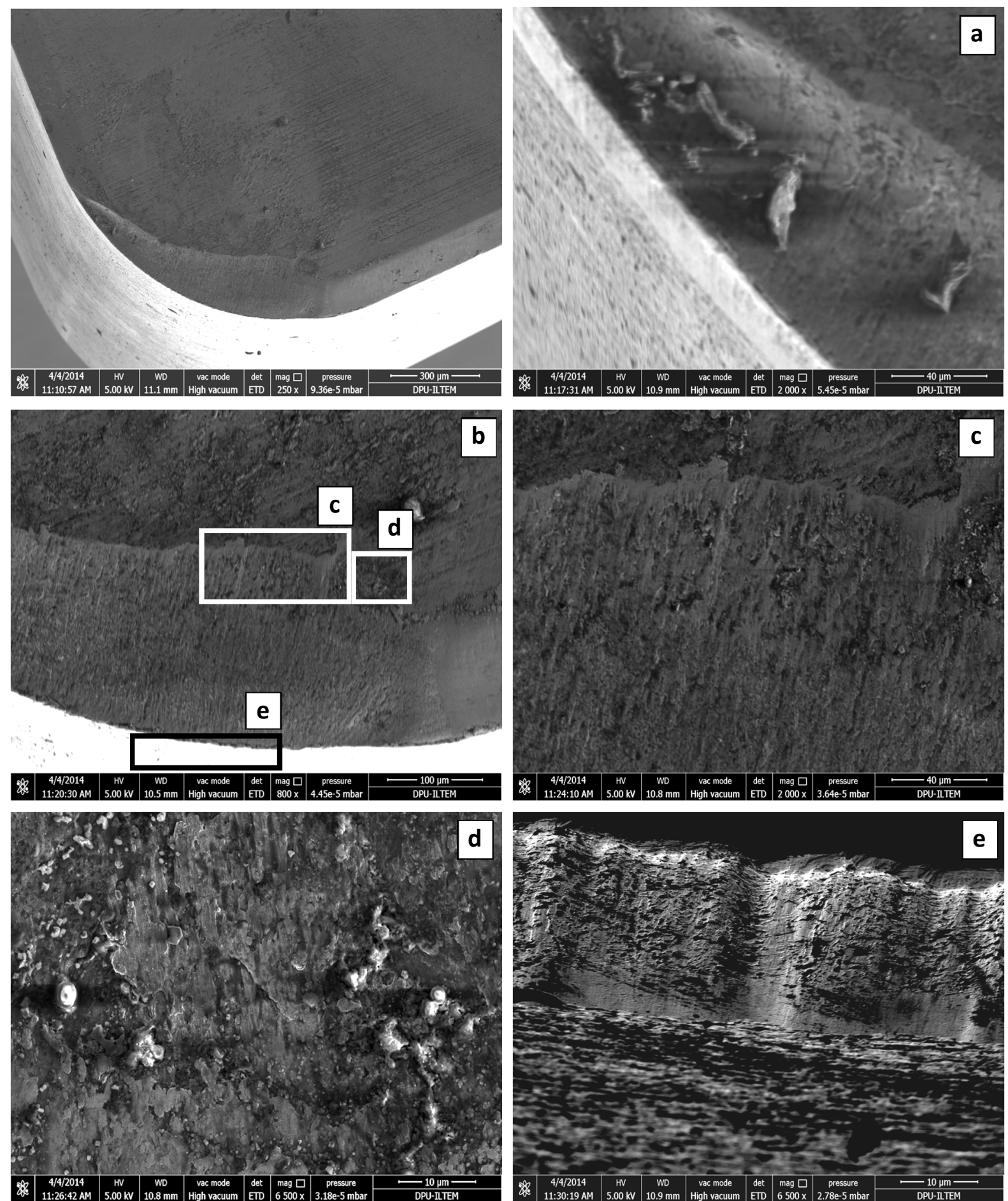

Şekil 2. SEM görüntüleri (Vc:270 m/dak, f:0,15 mm/dev, ap:0,4 mm) (SEM images (Vc:270 m/min, f:0.15 mm/rpm, ap:0.4 mm)

Tornalama deneylerinin ardından parçaların işlenmiş yüzeylerinden ölçülen $\mathrm{Ra}$ değerlerinin kesme parametreleri ile arasındaki ilişkinin tespit edilmesi amacı ile yüzey grafikleri (Sekil 3) varyans analizi (Tablo 3) ve ana etki grafikleri (Şekil 4) kullanılmıştır.

İlk olarak Şekil 3a ve $3 b$ 'de verilen grafikler ele alındığında, ilerleme ve kesme derinliği değerlerindeki artışa bağlı olarak Ra değerleri de artı̧̧ göstermiştir. Kesme hızındaki artış beklendiği gibi küçük bir oranda pürüzlülük değerinin iyileşmesini sağlamıştır. Kesme hızındaki artış kesme bölgesinde talaşın deformasyonunu kolaylaştırdığından pürüzlük üzerinde önemli katkılar sağlamaktadır [6]. En düşük yüzey pürüzlülüğü, kesme hızının $270 \mathrm{~m} / \mathrm{dak}$, ilerlemenin $0,05 \mathrm{~mm} / \mathrm{dev}$ ve $0,1 \mathrm{~mm}$ kesme derinliği değerlerinde elde edilmiştir. Deneylerde kullanılan kesme parametrelerinin Ra sonuçlarının değişimi üzerinde nasıl bir etkisinin olduğunu tespit etmek amaciyla Tablo 3'teki ANOVA analizleri ve Sekil 4 'teki ana etki grafiği hazırlanmıştır. Bunlara göre 
istatistiksel olarak \% 95 güven düzeyinde, en etkin parametrenin kesme derinliği (P:0,000, F:16,86) olduğu görülmüştür. Verilen "P" değeri önem düzeyini göstermektedir. \% 95 güven düzeyi için "P" değeri \% 5 olacaktır. Yani “P” değeri 0,05’ten küçük olan değerler istatistiksel olarak sonuç üzerinde önemli etkiye sahip olurken büyük olanlar önemsiz olacaktır.

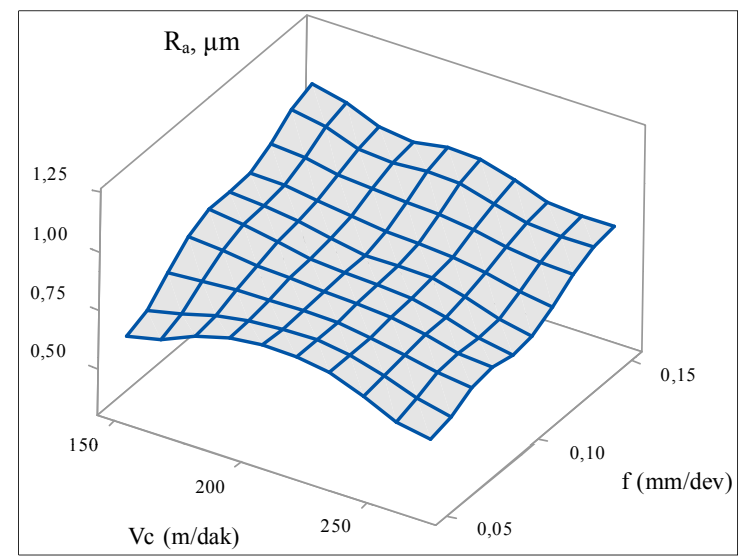

a) Kesme hizı ve ilerleme (Cutting speed and feed rate)

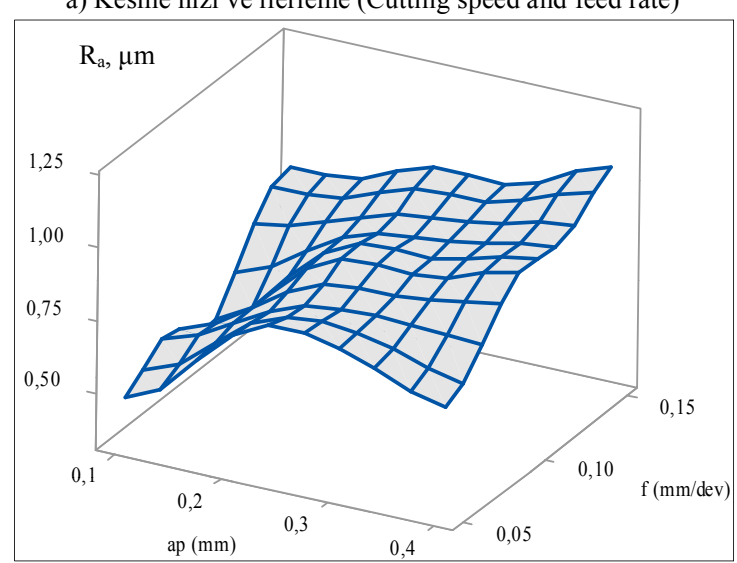

b) Kesme derinliği ve ilerleme (Depth of cut and feed rate)

Şekil 3. Yüzey pürüzlülüğü için yüzey grafikleri (Surface graphics for surface roughness).

İlerleme değerlerindeki değişimler de P:0,001, F:1,22 değerleri ile istatistiksel olarak $\mathrm{Ra}$ değişimleri üzerinde etkin olmaktadırlar. Kesme derinliği ve ilerleme değerleri arasında Ra sonuçları üzerindeki etkileri açısından belirgin bir fark görülmemiştir.
Kesme hızının istatistiksel olarak P:0,053 değeri ile yüzey pürüzlülüğü üzerinde önemli bir etkisi görülmemektedir. Yine de Vc'nin P değeri çok sınırda bir değer göstermiştir. Grafik yüzeylerindeki eğimler dikkate alındığında, kesme derinliğinin $\mathrm{Ra}$ üzerinde diğer parametrelerden daha belirgin değişimlere yol açtığ 1 söylenebilir. $\mathrm{Bu}$ durumun kesme derinliğinin azaldığı durumlarda kesme kuvvetlerinin ve titreşim eğiliminin etkisiyle ilgili olduğu düşünülmektedir. Şekil 4'te verilen ana etki grafiği de yukarıda açıklananları desteklemektedir. Grafikteki kesme hızı, ilerleme ve kesme derinliği eğrilerine bakılırsa, Kesme hızı eğrisi, ortalama çizgisine (kesik çizgi) çok yakın konum almıştır. Kesme hızında $210 \mathrm{~m} /$ dak'dan 270 m/dak'ya çıkıldığında Ra değerinde belirgin bir iyileşme gözlemlenmiştir. İlerleme değerinin değişimleri ile orantılı bir pürüzlülük değişimi görülmektedir. $0,1 \mathrm{~mm}$ kesme derinliğinde en düşük $\mathrm{Ra}$ değeri varken, $0,25 \mathrm{~mm}$ kesme derinliğine geçildiğinde $\mathrm{Ra}$ değerinde belirgin bir kötüleşme görülmüştür. $\mathrm{Bu}$ durum talaş kesitindeki belirgin artış ile ilişkilendirilebilir. İdeal Ra değeri için, 270 m/dak, ilerlemenin $0,05 \mathrm{~mm} / \mathrm{dev}$ ve $0,1 \mathrm{~mm}$ kesme derinliği değerleri önerilebilir. Ra değerinin tahmini amacıyla oluşturulan regresyon modeli Eşitlik 1'de verilmiştir. Tablo 4'te regresyon eşitliğindeki değişkenlerin sonuçlar üzerindeki etkilerini belirlemek için yapılan ANOVA analizi verilmiştir. Sonuçlara göre, hem önerilen model hem de her üç değişken istatistiksel olarak önemlidir. Buna göre Ra nın değişiminin \% 65,14'ü bağımsız değişkenler tarafından açıklanırken geriye kalan k1smin ise bu modele katılmayan değişkenlerce belirlendiği söylenebilir. Kurulan modelin tahminde kullanılabilmesi artıkların analizi mantıksal bir anlama sahip olmadıkça söz konusu değildir [22]. Şekil 5'te verilen grafik ise model sonuçları ile gerçek değerler arasındaki farklardan yola çıkılarak hesaplanmaktadır. Grafikte noktaların doğruya yakın olarak dağılım göstermeleri oluşturulan modelin istatistiksel olarak önemli olduğuna işaret etmektedir [23]. Bu grafik incelendiğinde, verilen modelin yeterli düzeyde önemli olduğu söylenebilir.

$\operatorname{Ra}(\mu \mathrm{m})=0,502-0,001168 \mathrm{Vc}(\mathrm{m} / \mathrm{dak})+2,825 \mathrm{f}$

$(\mathrm{mm} / \mathrm{dev})+1,036 \mathrm{ap}(\mathrm{mm})$

$\mathrm{R}^{2}=65,14$

Tablo 3. Ra değerleri için ANOVA sonuçları (ANOVA results for Ra values)

\begin{tabular}{lccccc}
\hline Parametreler & $\begin{array}{c}\text { Serbestlik derecesi } \\
\text { (DF) }\end{array}$ & $\begin{array}{c}\text { Kareler Toplami } \\
(\mathrm{SS})\end{array}$ & $\begin{array}{c}\text { Kareler ortalamasi } \\
(\mathrm{MS})\end{array}$ & $\mathrm{F}$ & $\mathrm{P}$ \\
\hline $\mathrm{Vc}(\mathrm{m} / \mathrm{dak})$ & 2 & 0,1113 & 0,05567 & 3,41 & 0,053 \\
$\mathrm{f}(\mathrm{mm} / \mathrm{dev})$ & 2 & 0,3661 & 0,18303 & 1,22 & 0,001 \\
ap $(\mathrm{mm})$ & 2 & 0,5500 & 0,27500 & 16,86 & 0,000 \\
Hata & 20 & 0,3263 & 0,01631 & & \\
Toplam & 26 & 1,3537 & & & \\
\hline
\end{tabular}




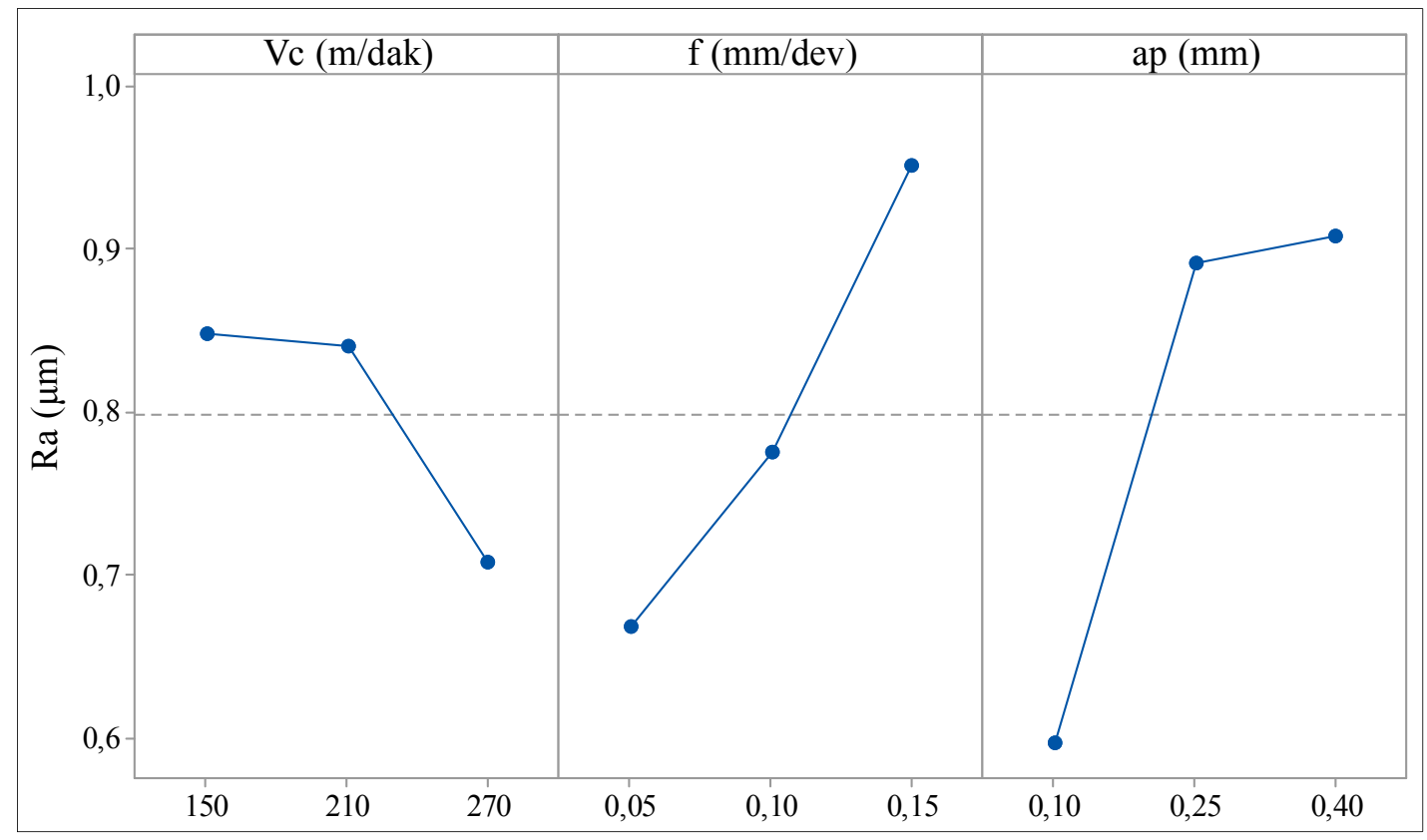

Şekil 4. Ra değerlerine göre ana etki grafiği (Main effect graphic according to the Ra values)

Tablo 4. Regresyon analizi için ANOVA sonuçları (ANOVA results for regression analysis)

\begin{tabular}{lccccc}
\hline Parametreler & $\begin{array}{c}\text { Serbestlik derecesi } \\
(\mathrm{DF})\end{array}$ & $\begin{array}{c}\text { Kareler Toplami } \\
(\mathrm{SS})\end{array}$ & $\begin{array}{c}\text { Kareler ortalamas } \\
(\mathrm{MS})\end{array}$ & $\mathrm{F}$ & $\mathrm{P}$ \\
\hline Regresyon & 3 & 0,88184 & 0,29395 & 14,33 & 0,000 \\
\hline Vc $(\mathrm{m} /$ dak$)$ & 1 & 0,08834 & 0,08834 & 4,31 & 0049 \\
$\mathrm{f}(\mathrm{mm} / \mathrm{dev})$ & 1 & 0,35908 & 0,35908 & 17,50 & 0,000 \\
ap $(\mathrm{mm})$ & 1 & 0,43442 & 0,43442 & 21,18 & 0,000 \\
Hata & 23 & 0,47183 & 0,02051 & & \\
Toplam & 26 & 1,35366 & & & \\
\hline
\end{tabular}

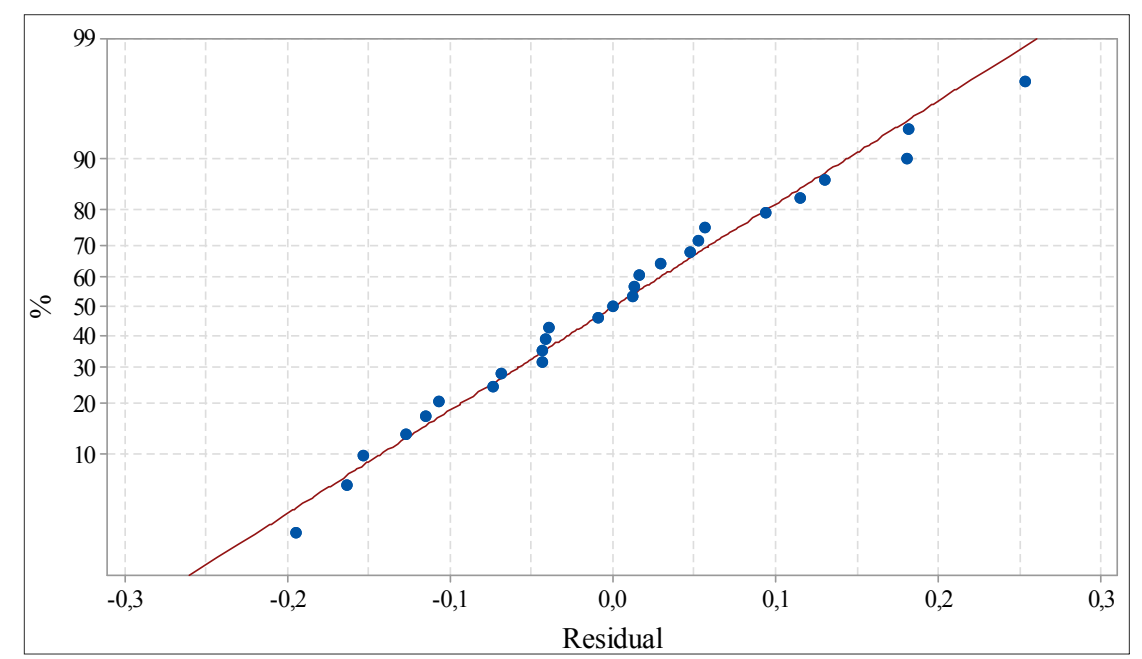

Şekil 5. Yüzey pürüzlülüğü Ra için normal olasılık grafiği (The normal probability plots for surface roughness Ra) 


\section{SONUÇLAR (CONCLUSIONS)}

Hazırlanan çalışmada, 60 HRC değerinde sertleştirilmiş PMD-23 toz metal çeliğinin işleme performansı, yüzey pürüzlülüğü ve takım aşınması açısından değerlendirilmiştir. Elde edilen bulgulara göre; kesici uçlara ait SEM görüntülerinin incelenmesi ile krater aşınması ve az miktarda da serbest yüzey aşınması görülmüștür. Ayrıca, mikro düzeyde iş parçası malzemesi yapışmaların olduğu ve dinamik şartlara bağlı olarak parçacık kopmalarının olduğu görülmektedir. Difüzyon ve abrasif aşınma mekanizmalarının bu aşınmaların oluşumu üzerinde etkili olduğu söylenebilir. İlerleme ve kesme derinliği değerlerindeki artışa bağlı olarak $\mathrm{Ra}$ değerleri artmıştır. Kesme hızının artışı pürüzlülüŭg̈ bir miktar iyileştirmiş̧tir.

ANOVA sonuçlarına göre Ra üzerindeki en etkin parametrenin kesme derinliği olduğu görülmüștür. İlerlemenin katkısı da kesme derinliğinin oluşturduğu katkıya çok yakın çıkmıştır. Ra değerlerinin tahmini amacıyla oluşturulan model ve değişkenleri istatistiksel olarak uygulanabilir ve önemli çıkmıştır. Bundan sonraki aşamalarda çalışma kapsamında yer almayan kesme kuvveti, talaş formu, titreşim gibi konular ele alınarak daha detaylı bir analiz yapılabilir. PMD-23 malzemesi ile ilgili daha detaylı işlenebilirlik bilgileri için, farklı kesici takım geometrileri, kaplama alternatifleri ve 1 sıl işlem şartları ile bunların frezeleme uygulamaları üzerine çalışmalar yapılabilir.

\section{SEMBOLLER VE KISALTMALAR (SYMBOLS AND ABBREVIATIONS)}

HRC: Rockwell C Sertliği (Hardness Rockwell C)

Ra: Yüzey Pürüzlülüğü, Aritmetik sapma (Aritmatical Surface Roughness)

ANOVA: Varyans Analizi (Analysis of Variance)

CBN: Kübik Bor Nitrür (Cubic Boron Nitride)

SEM: Taramalı Elektron Mikroskopu (Scanned Electron Microscope)

T/M: Toz Metal (Powder Metal)

HB: Brinell Sertliği (Hardness of Brinell)

f: $\quad$ ilerleme (feed)

Vc: Kesme hizı (Cutting Speed)

ap: Kesme derinliği (Depth of cut)

Rz: Yüzey pürüzlülüğü, ortalama pürüz yüksekliği (Surface Roughness Average roughness height)

TiN: Titanyum Nitrür (Titanium Nitride)

DF: $\quad$ Serbestlik Derecesi (Degree of Freedom)

SS: Kareler Toplamı (Sum of Squares)

MS: Kareler Ortalamas1 (Mean of Squares)

F: $\quad$ F test istatistiği (F-test)

P: $\quad$ Olasılık Düzeyi (Probability)

VB: Serbest yüzey aşınması (Flank wear)

\section{KAYNAKLAR (REFERENCES)}

1. Kalpakjian, S.S., S. R., Manufacturing engineering and technology fourth edition, Prentice Hall, New Jersey, 2001.

2. Grover, M.P., Fundementals of modern manufacturing Wiley, New York, 1999.

3. Danninger, A.S.M.S.H., Machinability of powder metallurgy steels, Cambridge, 2004.

4. Aksoy, T., Thesis, Kırıkkale University, 2009. Investigation of cutting tool performance and chip geometry in machining PMD 23 steel produced by powder metallurgy, M.Sc, Investigation of cutting tool performance and chip geometry in machining PMD 23 steel produced by powder metallurgy, Institute of Science, 2009.

5. Kaçal, A., "Investigation of Cutting Performance of the Ceramic Inserts in Terms ofthe Surface Roughness and Tool Wear at Turning of PMD 23 Steel”, Applied Mechanics and Materials, Cilt 686, 10-16, 2014.

6. Bingul, E. ve Kacal, A., "Hard Turning of Powder Metallurgical Cold Work Tool Steel Tempered in Different Tempering Temperature", Journal Of Scientific \& Industrial Research, Cilt 72, No 8, 498-505, 2013.

7. Çetinkaya, S.K., A., "Investigation of the heat treatment effect in millingof K390 powder metallurgical steel", Kovove Materialy-Metallic Materials, No 52, 209-218, 2014.

8. Suresh, R., Basavarajappa, S., Gaitonde, V.N. ve Samuel, G.L., "Machinability investigations on hardened AISI 4340 steel using coated carbide insert", International Journal of Refractory Metals \& Hard Materials, Cilt 33, 75-86, 2012.

9. Singh, D. ve Rao, P.V., "A surface roughness prediction model for hard turning process", International Journal of Advanced Manufacturing Technology, Cilt 32, No 11-12, 1115-1124, 2007.

10. Sood, R.G., C Malkin,S, "Turning of Hardened Steels", Journal of Manufacturing Processes, Cilt 2, No 3, 187-193, 2000.

11. Bartarya, G. ve Choudhury, S.K., "Effect of cutting parameters on cutting force and surface roughness during finish hard turning AISI52100 grade steel", Fifth Cirp Conference on High Performance Cutting 2012, Amsterdam, 651656.

12. Aouici, H., Yallese, M.A., Chaoui, K., Mabrouki, T. ve Rigal, J.F., "Analysis of surface roughness and cutting force components in hard turning with CBN tool: Prediction model and cutting conditions optimization", Measurement, Cilt 45, No 3, 344-353, 2012.

13. Asilturk, I. ve Akkus, H., "Determining the effect of cutting parameters on surface roughness in hard turning using the Taguchi method", Measurement, Cilt 44, No 9, 1697-1704, 2011. 
14. Poulachon, G., Bandyopadhyay, B.P., Jawahir, I.S., Pheulpin, S. ve Seguin, E., "Wear behavior of $\mathrm{CBN}$ tools while turning various hardened steels", Wear, Cilt 256, No 3-4, 302-310, 2004.

15. Lalwani, D.I., Mehta, N.K. ve Jain, P.K., "Experimental investigations of cutting parameters influence on cutting forces and surface roughness in finish hard turning of MDN250 steel", Journal of Materials Processing Technology, Cilt 206, No 1-3, $167-$ 179, 2008.

16. Grzesik, W., "Influence of tool wear on surface roughness in hard turning using differently shaped ceramic tools", Wear, Cilt 265, No 3-4, 327-335, 2008.

17. Dogra, M.S., V. S. Durejac, J, "Effect of tool geometry variation on finish turning - A Review", Journal of Engineering Science and Technology Review, Cilt 4, No 1, 1-13, 2011.

18. Hessainia, Z., Belbah, A., Yallese, M.A., Mabrouki, T. ve Rigal, J.F., "On the prediction of surface roughness in the hard turning based on cutting parameters and tool vibrations", Measurement, Cilt 46, No 5, 1671-1681, 2013.
19. Kacal, A. ve Yildirim, F., "Application of grey relational analysis in high-speed machining of hardened AISI D6 steel", Proceedings of the Institution of Mechanical Engineers Part CJournal of Mechanical Engineering Science, Cilt 227, No 7, 1566-1576, 2013.

20. Çakır, M.C., Modern Talaşı İmalatın Esasları, Nobel Yayın Dağıtım, 9755919791, 2007.

21. More, A.S.J.W.B., W. D. Malshe, A. P., "Tool wear and machining performance of CBN-TiN coated carbide inserts and PCBN compact inserts in turning AISI 4340 hardened steel", Journal of Materials Processing Technology, No 180, 253262, 2006.

22. K, Ö., Paket Programlar ile İstatistiksel Veri Analizi, 4. Baskı, Kaan Kitabevi, 2002.

23. Sahoo, A.K.S., B., "Performance studies of multilayer hard surface coatings (Tin/TiCN/Al2O3/TiN) of indexable carbide inserts in hard machining:Part-II (RSM, grey relational and techno economical approach)", Measurement, Cilt 46, No 8, 2868-2884, 2013. 
